\title{
How does Omnichannel Integration Quality Affect Consumers' Stickiness Intention
}

\author{
Eugenia Y. Huang \\ Department of Management \\ Information Systems \\ National Chengchi University \\ huang.eugenia@gmail.com
}

\author{
Sheng-Wei Lin \\ Department of Computer \\ Science and Information \\ Management \\ Soochow University \\ swlin@csim.scu.edu.tw
}

\author{
Kai-Teng Cheng \\ Department of Management \\ Information Systems \\ National Chengchi University \\ kai820191@gmail.com
}

\begin{abstract}
The popularity of mobile devices and the advancement of modern technology have resulted in more diversified consumer shopping channels, and many retailers have consequently embraced omnichannel retailing. The core concept of omnichannel retailing is to provide consumers with a seamless experience. Using commitment-trust theory as a framework, this study examines the effects of omnichannel integration quality on consumers' stickiness intention. Analysis of data of 194 respondents reveals that consumer trust affects relationship commitment. Consumer trust and relationship commitment have a strong influence on stickiness intention, and breadth, transparency, and process consistency directly affect trust. Contrary to our expectation, omnichannel integration quality does not affect relationship commitment. Our results show that high levels of omnichannel integration quality can increase consumer trust, which helps retailers maintain favorable customer relationships. The findings of this study provide important theoretical and practical implications for omnichannel retailing research.
\end{abstract}

\section{Introduction}

On July 17, 2017, Amazon acquired Whole Foods Market for US\$13.7 billion, a business move that shocked the market and created much discussion [1]. The forays by Amazon into offline retail have been a product of the increasingly blurred lines between online and offline retail channels caused by the prevalence of mobile devices. This prevalence enables consumers to easily switch between retail channels when making a purchase, leading to the emergence of omnichannel retailing [2]. Amazon observed the need to transform existing retail models and decided to integrate its online and offline retail channels to provide a new customer experience driven by product attributes and consumer behaviors. This decision marked the beginning of the era of omnichannel retailing.

Multiple differences can be found between multichannel and omnichannel retailing. Traditional multichannel retailers often suffer from problems relating to operational strategy and performance. For example, information asymmetry or flow-process discrepancy may cause trouble for consumers if the level of integration and cooperation is low among retail channels. This can result in intense competition between online and offline channels owned by the same retailer. Several studies have proposed channel integration strategies as a solution to this problem [3] [4] [5] [6].

Sousa and Voss [5] proposed the concept of integration quality, claiming that retailers must provide consumers with a seamless experience when their customers switch between retail channels. However, mobile devices with Internet access were less prevalent when multichannel retailing was enjoying its strongest growth, and consumers could not easily switch between online and offline channels. Consequently, retailers focused more on whether they were providing sufficient channels for their consumers, rather than on forming an interconnective relationship between all channels to create a seamless customer experience. Studies on multichannel retailing have primarily examined the integration of brick-and-mortar stores and e-commerce websites without incorporating the rise of mobile shopping channels (e.g., through APPs and QR codes). The concept of integration quality proposed by Sousa and Voss was developed exclusively for multichannel retaining; thus, their work cannot adequately explain how omnichannel retailing companies provide seamless customer experiences. To 
do so, the initial stages in the development of omnichannel retailing must be reexamined.

Retailers benefit from an understanding of customer loyalty in e-commerce and mobile commerce because such loyalty is associated with their business and operational performance [7] [8] [9]. Several studies have used customer intention to revisit and stickiness intention as proxy variables for customer loyalty [10] [11] [12] [13] [14]. However, these studies have only discussed the effects of online channels on customer loyalty without examining both the online and offline scope of omnichannel retailing. Although integration is the key to success in omnichannel retailing, it has rarely been touched upon in studies on e-commerce and mobile commerce. Furthermore, customer loyalty in omnichannel retailing has rarely been examined. Therefore, the present study considers the effects of integration quality in omnichannel retailing on customer loyalty to be a topic worthy of investigation. Accordingly, this paper examines the interaction between consumers and the various channels offered by a retailer to understand whether consumers' perceptions of integration quality affect their trust and commitment toward that retailer, thereby determining stickiness intention. Using the commitment-trust theory as a framework, this study investigates whether consumers' perceptions of integration quality affect their trust, commitment, and stickiness intention toward a retailer.

\section{Literature review}

\subsection{Omnichannel retailing}

Modern consumers have access to an increasing number of shopping channels. Many retail businesses no longer rely on physical stores but have started to integrate various channels such as physical retail stores and electronic, mobile, and social media channels, enabling customers to select their preferred shopping channel. However, the current trend within ecommerce has gradually blurred the distinction between physical and virtual shopping; in fact, retail transactions often cannot be identified as either online or physical. For example, if a consumer is unable to find a desired product in a physical store, they may ask a member of staff to order the product from the retailer's website for in-store pickup [15]. Is this transaction considered an online or offline transaction? Several scholars have also suggested that retail businesses adopt a consumer perspective and integrate all channels into one system [2] [16] [17] [18]. Such a system would enable consumers to instantly access retail businesses at any place and at any time, making purchases with various methods of payment and pickup. Consumers could select the most suitable shopping mode according to their needs by conveniently switching channels and attaining a seamless customer experience. This is how omnichannel retailing emerges. Beck and Rygl [19] defined this type of retailing as "the set of activities involved in selling merchandise or services through all widespread channels, whereby the customer can trigger full channel interaction and/or the retailer controls full channel integration."

Studies on multichannel retailing have explored many topics, including price consistency between physical retail stores and e-commerce websites [20] [21] [22] [23] [24] and the effects of retail channel integration on firm performance under six integration indicators [25]. However, the scope of these studies on the influence of channel integration on retail performance has been restricted to the integration of physical stores and e-commerce websites; research has only recently begun to incorporate mobile channels due to the rise of mobile devices [26].

Technological advances have increasingly diversified the type of retail channels available to consumers. For retailers, adding new retail channels is both a challenge and a double-edged sword. Integrating the new channels successfully can increase synergy and thereby improve retail performance. However, failure to do so results in cannibalization between retail channels, which ultimately leads to losses outweighing gains [27]. Nonetheless, previous studies have restricted their discussions to the relationship between channel integration and retail performance.

Increasing business profits cannot be achieved overnight; it requires continuous consumer- retailer interaction. In the age of omnichannel retailing, retailers all strive to increase profits by maximizing consumers' intention to revisit and repurchase, regardless of the channel used, in order to increase profits. In this study, stickiness intention is used as a crucial indicator of consumers' intention to revisit or repurchase, and it is argued that this indicator can be used to reflect the interaction and relationship between consumers and retailers.

\subsection{Omnichannel integration quality}

Consumers were often confused by how retailers operated their businesses in the era where multichannel retailing was dominant. In this era, both single-channel and multichannel retailers tended to adopt retailercentric business models. Several scholars have noted the drawbacks of independent retail channels (i.e., asymmetry of information between channels under the same retailer caused by lack of communication between departments across channels, resulting in 
inconsistent operation procedures) and recommended that such retailers transition into omnichannel retail [2] [28] [29]. Omnichannel retailing is a consumer-centric business model [2] [16] [17] [18]. The aforementioned concept of integration quality by Sousa and Voss [5] best describes how this model operates; unlike the traditional multichannel retail model, which can cause inconvenience to consumers because of isolated retail channels, the omnichannel retail model provides a consistent consumer experience through retail services from businesses with adequate integration quality. Sousa and Voss defined integration quality as "the ability to provide customers with a seamless service experience across multiple channels." They proposed two dimensions under integration quality: channelservice configuration and integrated interactions. Channel-service configuration can be assessed through two indicators: breadth of channel choice and transparency of the existing channel-service configuration. The breadth of channel choice refers to the degree of understanding a customer has regarding a service offered by the various channels under a retailer. The transparency of the existing channel-service configuration refers to the degree of channel transparency that enables consumers to distinguish channels according to their features and thereby seamlessly interact and transact with retailers. Integrated interactions can be categorized into two indicators, namely content consistency and process consistency. The content consistency means that consumers receive the same information from the retailer even when they transact with various channels, and the process consistency means that consumers perceive the service processes they have received as consistent when they access the retailer through different channels. Although the concept of integration quality proposed by Sousa and Voss was developed at a time when the multichannel retailing model was dominant and mobile devices with Internet access were uncommon, their model contains the same concept as the omnichannel business model: to provide a seamless consumer experience through retail services. Therefore, reexamining and modifying this concept by incorporating elements associated with the latest trends of omnichannel retailing is necessary. Also, the present study modified the concept of integration quality by renaming "integration quality," "breadth of channel choice," and "transparency of the existing channelservice configuration" as "omnichannel integration quality," "breadth," and "transparency."

\subsection{Commitment-trust theory}

First proposed by Morgan and Hunt [30], the commitment-trust theory addresses long-term relational exchanges and is a crucial theory in relationship marketing studies. Relationship commitment and trust are key constructs of sustaining relationships with consumers when companies perform marketing campaigns designed to establish, form, and maintain proper relational exchanges. Relationship commitment means an exchange partner believes that maintaining a long relationship with another partner is critical and therefore invests maximum effort in sustaining the relationship. In such a situation, the committed partner considers the relationship worth maintaining and strives to ensure it will last [30] [31]. Trust means that one of the committed parties believes in an exchange partner's reliability and integrity [30], and this serves as the foundation of the relational exchange [32]. Confidence in an exchange partner increases a party's willingness to rely on that partner [31]. In relationship marketing, these two constructs exert substantial influence on the success of relational exchange. Because they are mediator variables, the commitment-trust theory is also referred to as the key mediating variable (KMV) model. According to Morgan and Hunt, the antecedent factors of the KMV model are relationship termination costs, relationship benefits, shared values, communication, and opportunistic behavior; the outcomes of the model are acquiescence, propensity to leave, cooperation, functional conflict, and uncertainty.

The commitment-trust theory has been applied to examining business-to-business (B2B) relationships, including relationships in telecommunications [33], health insurance [34], and accommodation industries [35]. The theory has also been employed to explore business-to-consumer (B2C) relationships (e.g., those in e-commerce) [10], consumer-to-business relationships (e.g., group buying websites) [36], and even crowdsourcing platforms [37] [38]. Li et al. [10] adopted the commitment-trust theory to investigate consumers' stickiness intention toward B2C commerce websites. Stickiness intention is the antonym of "propensity to leave," an outcome variable commonly employed in commitment-trust theory. The propensity to leave is defined as the likelihood of terminating a prospective relational exchange in an exchange partner. A lower propensity to leave indicates a higher stickiness intention. Stickiness intention was regarded as repetitive visits to and use of a certain website because of a commitment to continue using that website [10]. Lin [11] regarded stickiness intention as the willingness to revisit a website and spend an extended period on that website. In other words, stickiness intention is the level of attachment to a preferred website [39] or a positive attitude toward the content, functions, products, and services featured on a website [13]. 
The objective of this study is to examine whether a retailer with well-integrated channels can create stickiness intention in its customers. According to the aforementioned literature, the commitment-trust theory has been extensively applied to both online and offline channel retail models for either B2B or B2C commerce. In addition, omnichannel retail models are applicable to $\mathrm{B} 2 \mathrm{C}$ commerce and feature an integration of online and offline channels. Thus, this study adopts the commitment-trust theory as its framework to investigate whether omnichannel integration quality is conducive to improving consumer commitment, trust, and stickiness intention toward a retailer.

\section{Research model and hypotheses development}

\subsection{Research model}

According to prior research and the aforementioned discussion, we employ the commitment-trust theory as the theoretical foundation for investigating how omnichannel integration quality influences consumer stickiness intention through relationship commitment and trust (Figure 1).

\subsection{Hypotheses development}

\subsubsection{Omnichannel integration quality, relationship commitment, and trust}

In the multichannel retail era, retailer channels owned by the same retailer often competed against each other. This competition negatively affected retailer profits and often confused consumers. Also consumers felt content or process inconsistency across channels. Inconsistency across channels reduces interaction between retailers and consumers. Therefore, in the early stages of developing omnichannel retailing, retailers integrate all channels to provide consumers with content and process consistency. This results in a common consensus between consumers and retailers. For retailer, providing the same information across different channels is one of the key elements for channel integration quality. For example, retailers holding a discount event for one day must ensure that the discount message appears across all channels. Retailers must provide consumers with a quick and smooth product browsing experience by publishing the message on all channels at the same time. Besides, consumers can choose their preferred channels and have a consistent and seamless shopping experience, assuming that retailers have numerous channels and high-quality channel integration. In addition, retailers can employ data analysis to find consumers interested in their products and provide them with personalized services for products they may enjoy. Retailers employing these tactics are able to compete with other retailers as long as consumers experience benefits from shopping with them. In the omnichannel retailing era, these are the goals that retailers must achieve.

Therefore, in this study, it can be reasonably inferred that consumers perceive that retailers show high performance and reliability as long as they uphold the principles of omnichannel retailing and provide high-quality channel integration. We argue that this increases consumer trust and commitment to retailers. Studies have confirmed that channel integration increases consumer trust in companies [4] [6] [40]. Sousa and Voss [5] also noted that integration is one of the key elements of service quality. High-quality service affects consumer commitment [41] and trust [42] [43] [44]. Therefore, we hypothesize that in an omnichannel retailing environment, high-quality channel integration, which can be perceived by consumers, leads to increased consumer trust and commitment to the retailer. Thus, hypotheses 1 and 2 are proposed as follows:

Hypothesis 1: The omnichannel integration quality of a retailer has a positive effect on consumers' relationship commitment.

Hypothesis 2: The omnichannel integration quality of a retailer has a positive effect on consumers' trust.

Because omnichannel integration quality comprises four indicators, namely breadth, transparency, content consistency, and process consistency, the hypotheses can be extended to the following subhypotheses:

Hypothesis 1a: The breadth of a channel has a positive effect on consumers' relationship commitment.

Hypothesis 1b: The transparency of a channel has a positive effect on consumers' relationship commitment.

Hypothesis 1c: The content consistency of a channel has a positive effect on consumers' relationship commitment.

Hypothesis 1d: The process consistency of a channel has a positive effect on consumers' relationship commitment.

Hypothesis 2a: The breadth of a channel has a positive effect on consumers' trust.

Hypothesis 2b: The transparency of a channel has a positive effect on consumers' trust.

Hypothesis 2c: The content consistency of a channel has a positive effect on consumers' trust.

Hypothesis 2d: The process consistency of a channel has a positive effect on consumers' trust. 


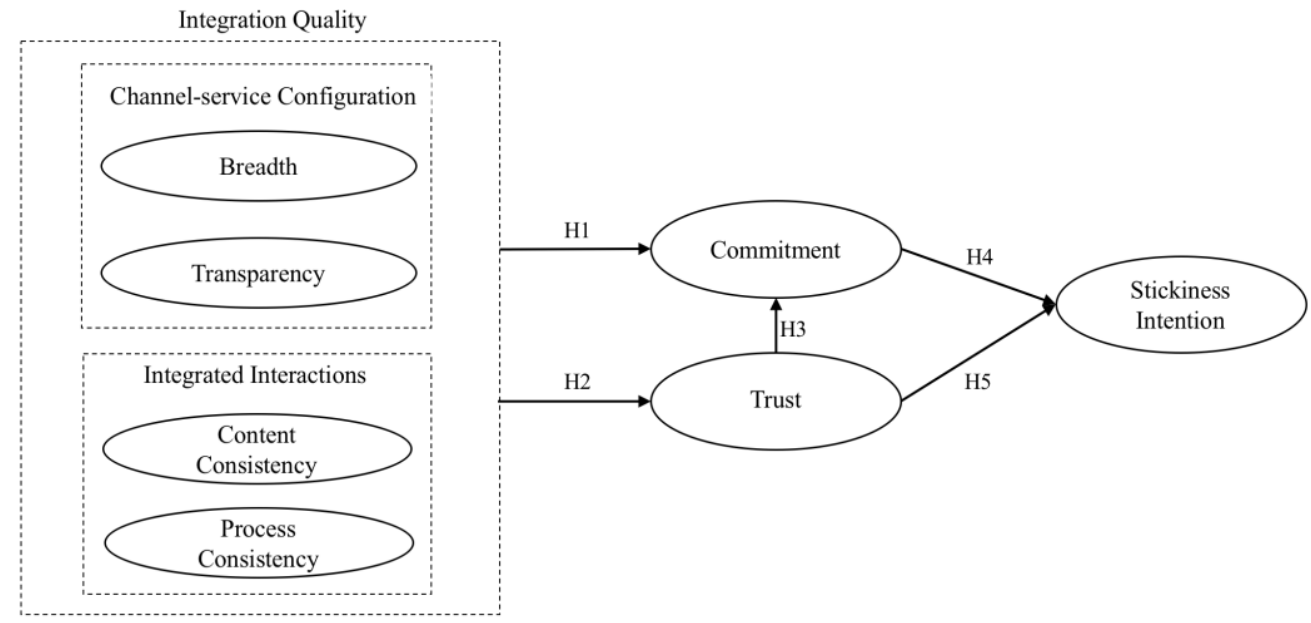

Figure 1. The research model

\subsubsection{Relationship commitment and trust}

Relationship commitment is a critical factor in relational marketing and is an explicit or implicit pledge between retailers and consumers [45]. However, relationship commitment is fragile. To maintain the relationship between retailers and consumers, a reliable partner is required on both sides [30]. When consumers believe that a retailer is reliable and trustworthy and that the retailer will not deceive them, the uncertainty and risk associated with that retailer will decrease [46], and consumers will seek to maintain a relationship with that retailer. The commitment-trust theory explains the relationship between trust and relationship commitment [30]. Moreover, studies have confirmed that trust affects relationship commitment [10] [13] [36]. Therefore, we argue that omnichannel retailers should provide diversified channels and seamless shopping experiences to consumers. If consumers feel positive about retailer performance and believe that a retailer is reliable and honest, they will maintain their relationship with that retailer. Therefore, we posit the following hypothesis:

Hypothesis 3: Consumers' trust in retailers has a positive effect on their relationship commitment.

\subsubsection{Relationship commitment, trust, and stickiness intention}

Stickiness intention refers to consumers who are deeply attached to retailers. This means that consumers maintain a relationship with retailers and continue to interact with them through various channels. Relationship commitment is an important factor that influences the relationship between retailers and consumers and is a driving factor of consumer interaction with retailers [47] [48]. Consumers who join a retailer's membership scheme can be considered to be committed to that retailer, indicating that consumers wish to maintain and enhance their relationship with the retailer [30]. Thus, consumers are more willing to visit a retailer repeatedly and increase their interaction with the retailer. Consumers will trust a retailer if they believe it is reliable and has integrity [30] and it has their confidence [31]. Therefore, trust is an important basis for maintaining the relationship between retailers and consumers [10].

The association among consumer relationship commitment, trust, and interaction with retailers has been discussed from numerous perspectives. In the marketing field, relationship commitment has been noted to positively influence consumers' intention to maintain a positive relationship with a retailer [49] [50]. Research on e-commerce has found that relationship commitment [10] and trust [10] [11] [13] affect stickiness intention. Therefore, we argue that in an omnichannel retailing environment, consumers wish to maintain their relationship with the retailer and believe that the retailer has superior service. Consequently, consumers continue to pay attention to the retailer and increase their revisits and interactions. Therefore, we posit the following hypotheses:

Hypothesis 4: Consumer relationship commitment has a positive effect on stickiness intention.

Hypothesis 5: Consumer trust has a positive effect on stickiness intention.

\section{Research methods}

\subsection{Data collection and study subjects}

To test the proposed model, we employed a quantitative survey method for collecting data to test 
the aforementioned hypotheses. Online surveys were administrated in this study. Respondents who had ever used specific retailer's online (including mobile channel) and offline services can fill out the questionnaire. In questionnaire, we firstly illustrated the definition of omnichannel retailing. Then, respondents were asked to choose the category of the omnichannel retailer that they had deep impression. In this study, respondents' perceptions of their omnichannel shopping experience were evaluated using a 5-point Likert scale, ranging from 1 (strongly disagree) to 5 (strongly agree). The data collection process lasted for 15 days, and a total of 214 responses were collected. After excluding 20 invalid samples, 194 questionnaires were used for further analysis.

The study sample comprised 101 females $(52.06 \%)$ and 93 males (47.94\%). The majority of participants were aged between 21 and 30 years $(71.65 \%)$, and the most common categories for their chosen retailers were cosmetics $(24.23 \%)$, apparel $(21.13 \%)$, electronics (19.59\%), and hypermarkets $(12.37 \%)$, which together accounted for $77.32 \%$ of the chosen retailers.

\subsection{Measurement}

The research model included seven constructs. To measure these constructs, we collected data through online survey. This section describes the measurement of each construct. Five items for breadth were adopted from Lee and Kim [51] to describe a channel's variety. The items used to measure transparency (three items) and process consistency (three items) were adopted from $\mathrm{Wu}$ and Chang [52]. We used five items adopted from $\mathrm{Oh}$ et al. [25] to measure content consistency. Seven items were adopted from Rusbult, Martz, and Agnew [53] to measure consumer relationship commitment. Five items for measuring trust were adopted from Morgan and Hunt [30], and seven items were adopted from $\mathrm{Li}$ et al. [10] and $\mathrm{Lin}$ [11] to measure consumer stickiness intention.

\subsection{Data analysis}

We conducted partial least square (PLS) analysis to test our hypotheses on the SmartPLS 2.0 (M3) software package [54]. This type of analysis is suitable for exploratory research [55], prediction, theory development, and small samples [56]. The purpose of the study is to examine the impact of omnichannel integration quality on consumer stickiness intention, which is an exploratory study. Thus, the study is suitable for partial least square analysis.

\section{Results}

\subsection{Measurement model}

Initial assessment of the model was conducted to identify items with indicators that did not have high significance in a t test and had reliability less than 0.7 [57]. The loadings of all items were significant and higher than the suggested indicator reliability benchmark of 0.70 , except for one item, which was excluded because of low loadings for the relationship commitment construct.

Reliability and validity were assessed using relationship commitment, trust, stickiness intention, and integration quality (breadth, transparency, content consistency, and process consistency).

The construct reliability of the measures was evaluated using Cronbach's alpha and composite reliability (CR). The Cronbach's alpha of each construct measure was as follows: breadth $=0.87$; transparency $=0.87 ;$ content consistency $=0.87$; process consistency $=0.84$; relationship commitment $=$ 0.92 ; trust $=0.87$; and stickiness intention $=0.93$. All values were higher than 0.7 and exceeded Hair's suggested threshold values [58].

We validated the measurement model by assessing content validity, convergent validity, and discriminant validity. We invited an e-commerce expert to review the instruments and validate the content. Convergent validity was evaluated by testing the $C R$ and average variance extracted (AVE) of the measurement. The CR value of all constructs was between 0.9 and 0.94 and was thus greater than the acceptable value of 0.7 [59]. The AVE also exceeded the recommended value of 0.5 [60]. The AVE values of all of the constructs ranged from 0.66 to 0.79 . Thus, the statistics demonstrated the high convergent validity of the model.

Discriminant validity was determined by assessing whether the square root of the AVE for each construct was greater than the correlations of the construct [60]. Table 1 presents the means, standard deviations, and correlations of all constructs. All of the correlations agreed with the square root of the AVE for each construct, which was greater than the inter-construct correlations, as shown on the diagonal in Table 1. Therefore, the model showed high discriminant validity. These results indicated that all of the constructs were acceptable and reliable.

\subsection{Structural model}

To validate the structural model, we used SmartPLS 2.0 to conduct PLS analysis. The results of structural path analysis are presented in Figure 2, 
revealing high explanatory variance for stickiness intention $\left(R^{2}=0.73\right)$, relationship commitment $\left(R^{2}=\right.$ $0.51)$, and trust $\left(\mathrm{R}^{2}=0.36\right)$.

As indicated in Figure 2, breadth, transparency, and process consistency had a significant effect on trust ( $\beta$ $=0.20, \mathrm{p}<.05 ; \beta=0.26, \mathrm{p}<.001 ; \beta=0.16, \mathrm{p}<.05)$, supporting Hypotheses $2 \mathrm{a}, 2 \mathrm{~b}$, and $2 \mathrm{~d}$. Contrary to our expectation, omnichannel integration quality had no direct influence on relationship commitment; thus, Hypothesis 1a-d were not supported. Trust $(\beta=0.66, \mathrm{p}$
$<.001)$ was a significant determinant of relationship commitment, indicating that trust has a strong influence on consumers' relationship commitment. Thus, Hypothesis 3 was supported. In addition, relationship commitment and trust $(\beta=0.49, \mathrm{p}<.001$; $\beta=0.44, p<.001)$ were positively related to consumer stickiness intention, supporting Hypotheses 4 and 5. In addition, path coefficients revealed that the direct effect of relationship commitment on stickiness intention was stronger than that of trust (0.49 vs. 0.44$)$.

Table 1. Means, standard deviations, and correlations between the constructs.

\begin{tabular}{llccccccccc}
\hline Construct & Mean & SD & 1 & 2 & 3 & 4 & 5 & 6 & 7 \\
\hline 1. & Breath & 3.99 & 0.65 & $\mathbf{0 . 8 1}$ & & & & & & \\
2. & Transparency & 3.83 & 0.79 & 0.72 & $\mathbf{0 . 8 9}$ & & & & & \\
3. & Content consistency & 3.69 & 0.78 & 0.40 & 0.41 & $\mathbf{0 . 8 1}$ & & & & \\
4. & Process consistency & 3.83 & 0.72 & 0.54 & 0.49 & 0.64 & $\mathbf{0 . 8 7}$ & & & \\
5. & Commitment & 3.55 & 0.68 & 0.43 & 0.44 & 0.23 & 0.36 & $\mathbf{0 . 8 4}$ & & \\
6. & Trust & 3.64 & 0.64 & 0.52 & 0.53 & 0.40 & 0.47 & 0.71 & $\mathbf{0 . 8 1}$ & \\
7. & Stickiness intention & 3.71 & 0.60 & 0.52 & 0.48 & 0.23 & 0.37 & 0.80 & 0.78 & $\mathbf{0 . 8 3}$ \\
\hline
\end{tabular}

Notes: The numbers in the diagonal in bold values are square roots of the AVE. Off-diagonal elements are the correlations among constructs.

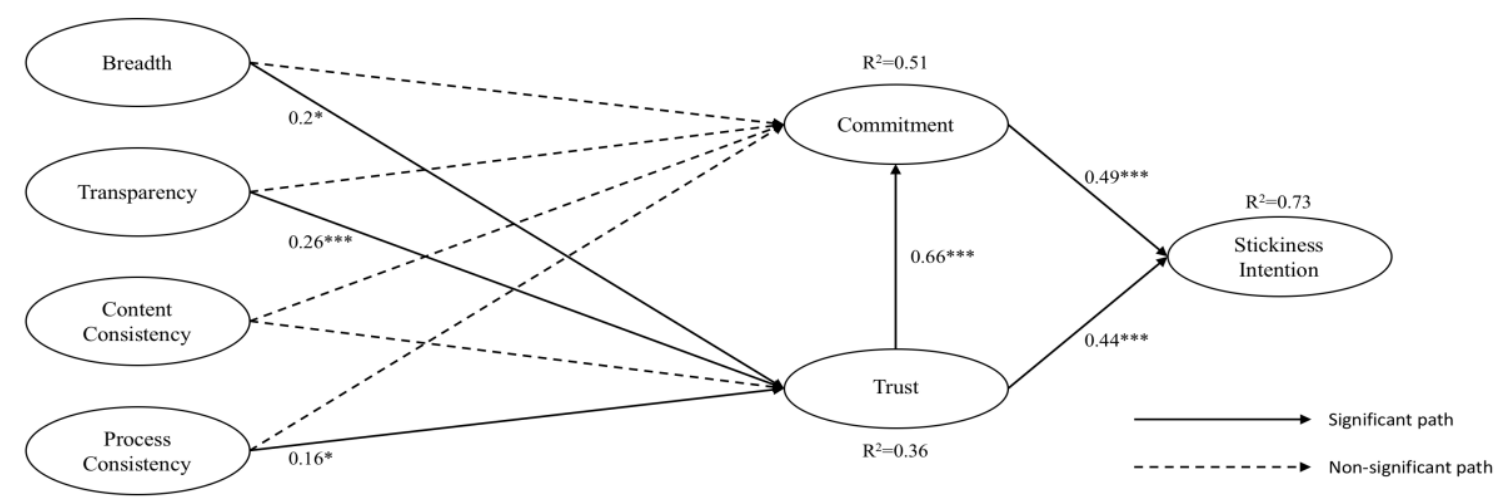

Figure 2. Results of the structural model.

(Note. $* \mathrm{p}<.05 . * * * \mathrm{p}<.001$.

This indicates that in the omnichannel retailing era, relationship commitment has more important effects on users' stickiness intention than trust.

\section{Discussion and implications}

Based on the commitment-trust theory, this study investigated the influence of omnichannel integration quality on consumer stickiness intention. The results confirmed that trust induced by breadth, transparency, and process consistency affected stickiness intention. Trust significantly and directly affected relationship commitment. In addition, both relationship commitment and trust had a positive effect on stickiness intention. The major findings of this study can be summarized as follows:

First, the relationship among relationship commitment, trust, and stickiness intention found in the current study is in line with the findings of previous research [10].

Second, the result showed that omnichannel integration quality did not affect relationship commitment. Based on the commitment-trust theory, relationship benefits positively affect relationship commitments. If consumers receive more benefits from a retailer, consumers will have a relationship commitment to that retailer. Currently, omnichannel 
retailing is in its initial stages. Thus, consumers are unlikely to clearly experience the benefits of channel integration by retailers. Only after experiencing retailers' efforts in channel integration and further building trust can consumers form a relationship commitment with retailers.

Third, the effect of breadth on trust found in the present study is consistent with the findings of previous research [61]. For example, Van Bruggen's [61] research in the field of marketing confirmed that more product brand distributors on a channel increases consumer trust in a company. This result is similar to that of the present study. Retailers can increase consumer trust by providing more channel alternatives; moreover, consumers are more trusting of retailers whose channel attributes are clearer. This finding is consistent with those of e-government research [62]. Citizens who clearly understand government processes or services have less uncertainty in processes and increased trust in the government; The relationship between process consistency and trust has been explored [63]. Hongyoun Hahn and Kim [63] argued that in the multichannel era, retailers must provide consistent services through both online and offline channels to win consumer trust.

Finally, contrary to our expectation, content consistency did not significantly affect trust. This result differs from that of multichannel research [4]. The omnichannel retailing era is in its initial stages. In an omnichannel retailing environment, consumers have high expectations of retailers and expect consistent information across channels. However, most retailers still have many inconsistencies across channels; thus, consumers may not trust retailers. Furthermore, the types of retailers chosen by respondents in the present study varied, with the major types being cosmetic, apparel, electronics, and hypermarkets. Each type of retailer likely has different business strategies for providing the same information across different channels, further eroding content consistency and therefore decreasing trust.

\subsection{Theoretical and practical implications}

The present results have numerous implications for research and practice. First, we contribute to the theoretical development of the omnichannel literature. We combined integration quality with commitmenttrust theory to understand consumer behaviors in the context of omnichannel retailing. Our findings indicate that consumers' stickiness intention depends on the degree to which retailer channels are perceived to be consistent and seamless.

Second, we confirm the effect of omnichannel integration quality on relationship commitment and trust. Our findings indicate that trust mediates the effects of breadth, transparency, process consistency, and relationship commitment. Thus, retailers should provide various channels to consumers, provide information on channel differences, and provide identical services regardless of the channel chosen by consumers. If retailers achieve these goals, consumers will be willing to trust and commit to them.

Third, the findings of this research can help retailers understand how the breadth of channel choice, transparency of existing channel-service configuration, and process consistency can evoke trust in consumers, thereby affecting their relationship commitment and stickiness intention. Based on the results, several suggestions can be provided to retailers. When consumers visit a physical store, the retailer can provide hints to consumers and help consumers understand which channels are available for browsing and shopping. In addition, retailers can help consumers understand the service characteristics of different channels (e.g., obtaining products through online channels requires a longer time than through physical stores). Furthermore, retailer service attitudes to customers in all channels cannot be different. Implementing the aforementioned recommendations can evoke consumers' trust in retailers.

\subsection{Limitations and directions for future research}

This study has several limitations. First, the types of retailers that the respondents had interacted with were mainly cosmetic, apparel, electronics, or hypermarket retailers $(77.32 \%)$. However, each type of retailer was less than the minimum number of samples required for PLS analysis [57]. Therefore, the overall model of a single type of retailer could not be analyzed. In addition, this study employed different retailers to analyze an overall model, which may explain why content consistency did not have a significant relationship with trust. Second, $71.65 \%$ of the sample was in the age range of 21-30 years. Therefore, the result may not be generalizable to other age groups.

Future research can explore other aspects related to omnichannel retailing issue (e.g., security or privacy) or examine the user's stickiness intention between different gender groups.

\section{Acknowledgements}

This research is partially funded by Ministry of Science and Technology, Taiwan, under contract number MOST 105-2410-H-031-036-MY3. 


\section{References}

[1] Amazon, "Amazon to Acquire Whole Foods Market", 2017, Retrieved from http://phx.corporateir.net/phoenix.zhtml?c=176060\&p=irol-

newsArticle \&ID=2281414

[2] D. R. Bell, S. Gallino, and A. Moreno, "How to win in an omnichannel world", MIT Sloan Management Review, 56(1), 2014, pp. 45-53.

[3] E. Bendoly, J. D. Blocher, K. M. Bretthauer, S. Krishnan, and M. A. Venkataramanan, "Online/in-store integration and customer retention", Journal of Service Research, 7(4), 2005, pp. 313-327.

[4] H. Schramm-Klein, G. Wagner, S. Steinmann, and D. Morschett, "Cross-channel integration-is it valued by customers?" The International Review of Retail, Distribution and Consumer Research, 21(5), 2011, pp. 501-511.

[5] R. Sousa, and C. A. Voss, "Service quality in multichannel services employing virtual channels", Journal of Service Research, 8(4), 2006, pp. 356-371.

[6] C. Steinfield, H. Bouwman, and T. Adelaar. "The dynamics of click-and-mortar electronic commerce: opportunities and management strategies", International Journal of Electronic Commerce, 7(1), 2002, pp. 93-119.

[7] D. Cyr, "Modeling web site design across cultures: relationships to trust, satisfaction, and e-loyalty", Journal of Management Information Systems, 24(4), 2008, pp. 47-72.

[8] J. V. Chen, D. C. Yen, W. Pornpriphet, and A. E. Widjaja, "E-commerce web site loyalty: A cross cultural comparison", Information Systems Frontiers, 17(6), 2015, pp. 1283-1299.

[9] S. Mithas, N. Ramasubbu, M. S. Krishnan, and C. Fornell, "Designing web sites for customer loyalty across business domains: A multilevel analysis", Journal of Management Information Systems, 23(3), 2006, pp. 97-127.

[10] D. Li, G. J. Browne, and J. C. Wetherbe, "Why do internet users stick with a specific web site? A relationship perspective", International Journal of Electronic Commerce, 10(4), 2006, pp. 105-141.

[11] J. C. C. Lin, "Online stickiness: its antecedents and effect on purchasing intention", Behaviour \& Information Technology, 26(6), 2007, pp. 507-516.

[12] S. K. Roy, W. M. Lassar, and G. T. Butaney, "The mediating impact of stickiness and loyalty on word-of-mouth promotion of retail websites: A consumer perspective". European Journal of Marketing, 48(9/10), 2014, pp. 1828-1849.

[13] J. J. Wu, Y. H. Chen, and Y. S. Chung, "Trust factors influencing virtual community members: A study of transaction communities", Journal of Business Research, 63(9), 2010, pp. 1025-1032.

[14] C. Zott, R. Amit, and J. Donlevy, "Strategies for value creation in e-commerce: best practice in Europe", European Management Journal, 18(5), 2000, pp. 463-475.

[15] D. Rigby, "The future of shopping", Harvard Business Review, 89(12), 2011, pp. 65-76.

[16] G. M. Fulgoni, "Omni-Channel Retail Insights and The Consumer's Path-to-Purchase". Journal of Advertising Research, 54(4), 2014, pp. 377-380.

[17] S. A. Neslin, D. Grewal, R. Leghorn, V. Shankar, M. L. Teerling, J. S. Thomas, and P. C. Verhoef, "Challenges and opportunities in multichannel customer management", Journal of Service Research, 9(2), 2006, pp. 95-112.

[18] S. Peltola, H. Vainio, and M. Nieminen, "Key factors in developing omnichannel customer experience with finnish retailers", In Proceedings of the 2nd International Conference on HCI in Business, 2015.

[19] N. Beck, and D. Rygl, "Categorization of multiple channel retailing in Multi-, Cross-, and Omni-Channel Retailing for retailers and retailing”, Journal of Retailing and Consumer Services, 27, 2015, pp. 170-178.

[20] F. Ancarani, and V. Shankar, "Price levels and price dispersion within and across multiple retailer types: Further evidence and extension", Journal of the Academy of Marketing Science, 32(2), 2004, pp. 176-187.

[21] J. Avery, T. J. Steenburgh, J. Deighton, and M. Caravella, "Adding bricks to clicks: Predicting the patterns of cross-channel elasticities over time", Journal of Marketing, 76(3), 2012, pp. 96-111.

[22] X. Pan, B. T. Ratchford, and V. Shankar, "Can price dispersion in online markets be explained by differences in etailer service quality?", Journal of the Academy of Marketing Science, 30(4), 2002, pp. 433-445.

[23] F. F. Tang, and X. Xing, "Will the growth of multichannel retailing diminish the pricing efficiency of the web?", Journal of Retailing, 77(3), 2001, pp. 319-333.

[24] X. Xing, Z. Yang, and F. F. Tang, "A comparison of time-varying online price and price dispersion between multichannel and dotcom DVD retailers", Journal of Interactive Marketing, 20(2), 2006, pp. 3-20.

[25] L. B. Oh, H. H. Teo, and V. Sambamurthy, "The effects of retail channel integration through the use of information technologies on firm performance", Journal of Operations Management, 30(5), 2012, pp. 368-381.

[26] L. Cao, and L. Li, "The impact of cross-channel integration on retailers' sales growth", Journal of Retailing, 91(2), 2015, pp. 198-216.

[27] P. C. Verhoef, Multichannel customer management strategy. In V. Shankar \& G. S. Carpenter. (Eds.), Handbook of Marketing Strategy, (pp. 135-150), Edward Elgar Pub, Cheltenham, 2012.

[28] W. Piotrowicz, and R. Cuthbertson, "Introduction to the special issue information technology in retail: Toward omnichannel retailing", International Journal of Electronic Commerce, 18(4), 2014, pp. 5-16.

[29] P. C.Verhoef, P. K. Kannan, and J. J. Inman, "From multi-channel retailing to omni-channel retailing: introduction to the special issue on multi-channel retailing", Journal of Retailing, 91(2), 2015, pp. 174-181.

[30] R. M. Morgan, and S. D. Hunt, "The commitment-trust theory of relationship marketing", The Journal of Marketing, 58(3), 1994, pp. 20-38.

[31] C. Moorman, G. Zaltman, and R. Deshpande, "Relationships between providers and users of market research: The dynamics of trust within and between organizations", Journal of Marketing Research, 29(3), 1992, pp. 314-328.

[32] M. Deutsch, "Trust and suspicion", Journal of Conflict Resolution, 2(4), 1958, pp. 265-279.

[33] M. Friman, T. Gärling, B. Millett, J. Mattsson, and R. Johnston, "An analysis of international business-to-business 
relationships based on the Commitment-Trust theory", Industrial Marketing Management, 31(5), 2002, pp. 403-409. [34] J. Cote, and C. Latham, "Hidden costs in the physicianinsurer relationship", Journal of Health Care Finance, 30(2), 2003, pp. 30-36.

[35] J. T. Bowen, and S. Shoemaker, "Loyalty: A strategic commitment", Cornell Hotel and Restaurant Administration Quarterly, 44(5-6) , 2003, pp. 31-46.

[36] W. T. Wang, Y. S. Wang, and E. R. Liu, "The stickiness intention of group-buying websites: The integration of the commitment-trust theory and e-commerce success model", Information \& Management, 53(5), 2016, pp. 625642.

[37] X. L. Shen, M. K. Lee, and C. M. Cheung, "Exploring online social behavior in crowdsourcing communities: A relationship management perspective", Computers in Human Behavior, 40, 2014. pp 144-151.

[38] K. F. Hashim, and F. B. Tan, "The mediating role of trust and commitment on members' continuous knowledge sharing intention: A commitment-trust theory perspective", International Journal of Information Management, 35(2), 2015, pp. 145-151.

[39] Y. H. Chen, S. H. Chien, J. J. Wu, and P. Y. Tsai, "Impact of signals and experience on trust and trusting behavior. Cyberpsychology", Behavior, and Social Networking, 13(5), 2010, pp. 539-546.

[40] K. Jiang, L. Xu, and X. Bao, "The impact of channel integration on channel reciprocity in the multi-channel retailing context", In Proceedings of the 22nd International Conference on Industrial Engineering and Engineering Management, 2015.

[41] G. Fullerton, "The service quality-loyalty relationship in retail services: does commitment matter?" Journal of Retailing and Consumer Services, 12(2), 2005, pp. 99-111.

[42] D. K. Ruyter, L. Moorman, and J. Lemmink, "Antecedents of commitment and trust in customer-supplier relationships in high technology markets", Industrial Marketing Management, 30(3), 2001, pp. 271-286.

[43] S. P. Gounaris, "Trust and commitment influences on customer retention: insights from business-to-business services", Journal of Business Research, 58(2), 2005, pp. 126-140.

[44] J. Park, J. Lee, H. Lee, and D. Truex, "Exploring the impact of communication effectiveness on service quality, trust and relationship commitment in IT services", International Journal of Information Management, 32(5), 2012, pp.459-468.

[45] F. R. Dwyer, P. H. Schurr, and S. Oh," Developing buyer-seller relationships", The Journal of marketing, 51(2), 1987, pp. 11-27.

[46] S. Ganesan, and R. Hess, "Dimensions and levels of trust: implications for commitment to a relationship", Marketing letters, 8(4), 1997, pp. 439-448.

[47] C. E. Rusbult, "A longitudinal test of the investment model: The development (and deterioration) of satisfaction and commitment in heterosexual involvements", Journal of Personality and Social Psychology, 45(1), 1983, pp. 101-117. [48] H. S. Bansal, P. G. Irving, and S. F. Taylor, "A threecomponent model of customer to service providers", Journal of the Academy of Marketing Science, 32(3), 2004, pp. 234250 .

[49] M. Wetzels, K. De Ruyter, and M. Van Birgelen, "Marketing service relationships: the role of commitment", Journal of Business \& Industrial Marketing, 13(4/5), 1998, pp. 406-423.

[50] E. Garbarino, and M. S. Johnson, "The different roles of satisfaction, trust, and commitment in customer relationships", Journal of Marketing, 63(2), 1999, pp. 70-87.

[51] H. H. Lee, and J. Kim, "Investigating dimensionality of multichannel retailer's cross-channel integration practices and effectiveness: shopping orientation and loyalty intention", Journal of Marketing Channels, 17(4), 2010, pp. 281-312.

[52] J. F. Wu, and Y. P. Chang, "Multichannel integration quality, online perceived value and online purchase intention: A perspective of land-based retailers", Internet Research, 26(5), 2016, pp. 1228-1248.

[53] C. E. Rusbult, J. M. Martz, and C. R. Agnew, "The investment model scale: Measuring commitment level, satisfaction level, quality of alternatives, and investment size", Personal relationships, 5(4), 1998, pp. 357-387.

[54] C. M. Ringle, S. Wende, and S. Will, "SmartPLS 2.0 (M3) Beta, Hamburg.", 2005, Retrieved from, http://www.smartpls.de.

[55] C. M. Ringle, M. Sarstedt, and D. W. Straub, "Editor's Comments: A critical look at the use of PLS-SEM in MIS quarterly", MIS quarterly, 36(1), 2012, pp. 3-14.

[56] J. Henseler, C. M. Ringle, and R. R. Sinkovics, "The use of partial least squares path modeling in international marketing", Advances in International Marketing, 2009, pp. 277-319.

[57] W. W. Chin, The Partial Least Squares Approach for Structural Equation Modeling. In George A. Marcoulides (Eds.), Modern Methods for Business Research, (pp. 295336), Lawrence Erlbaum Associates, Mahwah, 1998.

[58] J. F. Hair, Multivariate Data Analysis. 7th ed., Prentice Hall, New Jersey, 2010.

[59] R. P. Bagozzi, and Y. Yi, "On the Evaluation of Structural Equation Models", Journal of the Academy of Marketing Science, 16(1), 1988, pp. 74-94.

[60] C. Fornell, and D. F. Larcker, "Evaluating Structural Equation Models with Unobservables and Measurement Error", Journal of Marketing Research, 18(1), 1981, pp. 3950.

[61] G. H. Van Bruggen, M. Kacker, and C. Nieuwlaat, "The impact of channel function performance on buyer-seller relationships in marketing channels", International Journal of Research in Marketing, 22(2), 2005, pp. 141-158.

[62] V. Venkatesh, J. Y. Thong, F. K. Chan, and P. J. Hu, "Managing citizens' uncertainty in E-government services: the mediating and moderating roles of transparency and trust", Information Systems Research, 27(1), 2016, pp. 87111.

[63] K. Hongyoun Hahn, and J. Kim, "The effect of offline brand trust and perceived internet confidence on online shopping intention in the integrated multi-channel context", International Journal of Retail \& Distribution Management, 37(2), 2009, pp. 126-141. 